Journal of English Language Teaching and Applied Linguistics

ISSN: 2707-756X

DOI: $10.32996 /$ jeltal

Journal Homepage: www.al-kindipublisher.com/index.php/jeltal

| RESEARCH ARTICLE

\title{
Transcending Lockdown: Teaching and Learning EFL during Covid-19 Crisis
}

\author{
Saeed, Aziz Thabit ${ }^{1}$, Al-Khatib, Hayat ${ }^{2}$, Abdel Hafeez, Ghada ${ }^{3} \square$ and Said, Kaldun ${ }^{4}$ \\ ${ }^{1}$ Dean of Faculty of Language Studies (FLS), Professor of Linguistics, Arab Open University-HQ, Kuwait \\ 2 Professor of Applied Linguistics, ELL Programme Coordinator, Arab Open University, Lebanon Branch \\ ${ }^{3}$ Professor of English Literature, FLS local dean, Arab Open University, Bahrain Branch \\ ${ }^{4}$ Lecturer of English, Arab Open University, Kuwait Branch
}

Corresponding Author: Abdel Hafeez, Ghada, E-mail: ghada.abdelhafeez@aou.org.bh

\begin{abstract}
| ABSTRACT
This study investigated the effectiveness of the adopted and adapted teaching methods, procedures and techniques in the virtual EFL classes during Covid-19 from the viewpoint of both learners and tutors. Data in the study were collected through two instruments: a tutor survey that elicited information from 42 randomly selected English language skills tutors, teaching at the English language foundation program at the nine branches of the Arab Open University (AOU); and a student survey that elicited information from 911 responding EFL learners enrolled in the foundation program. The tutor survey drew data pertaining to the teaching practices utilized by the tutors in their virtual teaching, their effectiveness, the extent to which learners were receptive to such practices, etc. The data collected through the learners' survey pertained to such matters as quality of internet connectivity, the effectiveness of the teaching procedures, interaction with tutors, assessments, etc. The study demonstrates that the tutors utilized a variety of teaching methods, techniques and procedures that were, as reported by participating tutors and learners, conducive to effective teaching and learning English despite some obstacles and that the tutors were quite pleased with the overall practice and outcome of the virtual teaching-learning process. The students' responses showed that, despite some technical hurdles, they were generally comfortable with the online mode of teaching and learning. This virtual style of teaching and learning is perceived to have more advantages than originally thought. The paper delineates the major findings of the study and concludes with implications and recommendations.
\end{abstract}

\section{| KEYWORDS}

Covid-19, EFL learners and teachers, teaching methods, assessments

| ARTICLE DOI: 10.32996/jeltal.2022.4.1.5

\section{Introduction}

The spread of the universal pandemic (Covid-19) has globally affected teaching and learning practices as well as assessments. The pandemic has necessitated modifying traditional in-class teaching methods and adopting and adapting procedures, techniques and teaching strategies deemed appropriate for online teaching, learning and assessments. Many studies were conducted at the advent of the pandemic and before the start of lockdown. One of these studies is that of Elers (2020), in which he reports, "Education institutions around the world are scrambling to prepare for online teaching and learning because of the coronavirus threat" (p.1). In the United Kingdom, he notes that most universities suspended face-to-face teaching and moved to online learning. The same thing occurred in the United States, where many universities, including most of the highest-ranked ones, such as MIT, Chicago, Princeton, Cornell, Pennsylvania, Yale, Columbia, and Johns Hopkins, moved to online teaching and learning. Eventually, all institutions moved to the e-learning mode. In the Arab world, higher education institutions followed suit from the beginning of the pandemic surge. The Arab Open University (AOU) took the decision to move to online teaching, owing to the spread of the pandemic, in the nine countries that host AOU branches: Kuwait, Saudi Arabia, Egypt, Jordan, Lebanon, Bahrain, Oman, Palestine and Sudan. While the transition to e-learning was definitely a challenging task for almost all institutions, the shift to remote teaching and learning was relatively smoother at the AOU because the University has adopted

Copyright: (c) 2022 the Author(s). This article is an open access article distributed under the terms and conditions of the Creative Commons Attribution (CC-BY) 4.0 license (https://creativecommons.org/licenses/by/4.0/). Published by Al-Kindi Centre for Research and Development, London, United Kingdom. 
blended learning since its inception. Blended learning at the AOU means that students engage in both face-to-face learnings, i.e. on-campus traditional class teaching, and independent, self-study mode in which students study by themselves a percentage of the content of the modules, supported by materials prepared by the teachers and posted for students on LMS. Again, the shift to e-learning was not as smooth for many institutions. According to Coman et al. (2020: 1-24), the shift to e-learning has presented many problems associated with course delivery, the degree of staff expertise, student resources and engagement. In a closer probing, the shift is argued to have a double impact on communication skills courses that require drills and in-class pace and space practices (Some-Guiebre 2020). In the wake of current research on the role of foreign language classroom setting in promoting communicative skills (Hu \& Zhang 2020; Vebriyanto 2015; Walsh 2011), some recent views advocated that "the nature of classroom interaction often determines the extent to which learners can or cannot acquire the language" (Some-Guiebre 2020: 1). During Covid-19 lockdown, EFL/ESL instructors had to deliver their sessions and assessments virtually and cope with a spectrum of new experiences and pedagogies that have presented challenges for both instructors and language learners. Zipin (2020: 111-115) noted a clear bias against online teaching, culminating in propositions that it would never match "the real thing."

Covid-19 has transformed higher education as well as influenced new demands and trends. Soft skills, an independent education and lifelong learning, have become increasingly important and have taken many forms during confinement. Research has started to target the new conditions under which teaching and learning took place, the basic purposes of education, and the pedagogic models that can serve the new context. In addition, the mounting concerns over the optimal conditions under which teaching and learning can be effective in crisis situations, like the lockdown forced by Covid-19, have made it necessary for educators and higher education institutions to engage in more research and reflection.

\section{Literature Review}

Covid-19 has had its impact on higher education at all levels. Owing to its impact, efforts have been conducted to investigate and evaluate the online teaching experience from the viewpoints of instructors, administrators and learners. One of such attempts is that of the Online Education Trends Report (OETR) (2021), which sought to collect information on teaching and learning through remote and online contexts during the Covid-19 pandemic by surveying a good representative sample of academic institutions and learners under lockdown. In its 2021 report, it states, "This year, we reached 1,800 participants, representing current remote and online learners, prospective online students, and online degree program graduates. These participants responded to questions about their learning experience, motivation and expectations, and overall satisfaction ..." (p. 5). The Report also followed on the challenges learners encountered during their online experience and underlined the following difficulties (OETR, 2021) "access to technology, i.e. "having access to the required technology or internet connectivity" as the first challenge reported by the students (p. 14). However, according to the OETR, the students surveyed in $2021(\mathrm{~N}=1800)$ reported positive views about online learning, with (74\%) of all students surveyed felt that "online learning was better than or equal to on-campus learning..." (p. 43). The report also indicates that "64\% of students who experienced online teaching for the first time due to covid-19 said it was better than or equal to on-campus learning" (p. 44).

The successful experience of online learning has motivated academic institutions administrators to advocate using the online learning system after Covid-19 is over. In this respect, OETR maintains, "Many administrators $(n=302)$ shared insights about how their institutions were planning to move forward once they are able to resume normal operations. One-third (33\%) planned to continue both remote and online course options for students, while $22 \%$ said their schools would pursue more online options in the future" (p. 27).

From another perspective, St.Amour (2020) argues that a demographic shift during times of Covid-19 is noticed, resulting in a major change in faculty and students' experiences. She contends that a new gap is materializing between faculty and students to the extent that students' experiences are starting to resemble less and less those of faculty members. The shift to online teaching and learning has reallocated education responsibilities with more weight allotted to learners. In terms of other noticeable changes, St. Amour's study (2020) reports that older students on a lower income are becoming the current university population. According to St. Amour's study (2020: 1), higher education in the times of Covid-19 has one-third of students older than 25 (37\%), out of which two-thirds (64\%) work while in college, another quarter or so are parenting while studying.

In terms of financial profiling of students during the Covid-19 crisis, St. Amour's study highlighted that less than half of students are now financially independent (49\%), while one-third live at or below the poverty level (31\%). St.Amour warned that the financial pressure on students is bound to chatter their attempts to concentrate on studying, as it continues to influence the world's economy. This, in turn, would exert more pressure on faculty to maintain and support students in higher education and should require attention from higher administration.

Some studies have focused on the support that instructors should receive during this universal pandemic in order to be able to handle their teaching duties efficiently. Stommel et al. (2020: 15), for instance, argued that in extraordinary conditions, colleges and universities need to provide more support and motivation to faculty members to help them face the emerging needs and 
provide the required assistance for their students. In our experience at AOU, in of campus context, faculty may be required to teach outside of typical daytime hours and exert support to students who would also need additional flexibility.

In the same vein, Jack (cited in Giano, 2020: 362-372) voices more or less the same stance, stating that under exceptional circumstances, educational institutions may need to undergo a serious shift to be able to accommodate extraordinary situations. Jack underlined new requirements from faculty and staff, stating that exceptional efforts are needed as well as a new alignment of faculty skills with students' needs.

The expectations of instructors and learners may vary under the current universal pandemic. In this respect, Jenkins (2020: 45-53) is of the opinion that more research is required on students and faculty expectations in situations of crisis and the role of academic institutions in supporting the two major stakeholders in the academic enterprise in times of crisis. The current situation may have allured some institutions to rely on adjunct instructors at the expense of permanent ones. This definitely can have negative consequences on the teaching and learning process. To this effect, we recall Kadlec (2006), who stressed that systematic adjunctification makes faculty feel undervalued and spawns low pay and instability, which in turn make it difficult for faculty to devote office follow up and support. Usually, adjunct faculty members are underpaid, and they do not enjoy a full package of incentives, as is the case with permanent faculty. Therefore, they do not develop a sense of loyalty and sense of belonging to the institution they are temporarily affiliated with. To this effect, Stommel et al. (2020) contend that the stresses ensuing from such precarious job position, which often provides little security and does not pay well, make experimentation with pedagogy and teaching difficult. The same study revealed that faculty members are themselves struggling with means of adapting to the crisis. Suppose instructors are satisfied in their jobs and are provided with the training support that is required to enable them to perform their duties efficiently. In that case, they will perform well both as instructors and as student advisors. Indeed, instructors are sometimes required to function as counsellors to their students, an issue that is essential, particularly during this pandemic period.

Some educational institutions have taken measures to train and support their staff by instating condensed workshops and offering training scenarios to support their faculty in the technical and out of campus assessment aspects. Others are providing technical and counselling support for their student body. Course delivery takes many forms ranging from synchronous to asynchronous activities. In addition, assessment is generating debate on the amount of compassionate rigour required in times of crisis as well as the required benchmarking (Metro, 2020:1). All of the above concerns mandate more research in pursuit of adequate measures in dealing with teaching and learning in difficult situations.

As for assessment, Gino (2016) and Karatas et al. (2013) maintain that creating conditions that reduce stress and test anxiety and generate a more compassionate experience can reflect a better measure of student learning. They argued that the more stressed out students are while taking a final exam or assessment, the less likely they are to perform at their true capacity. By designing final assessments that measure course-learning objectives and align with the characteristics of the future contexts in which students would need to apply their knowledge, can help institutions ensure that their assessments can be reflective of their students' preparedness and knowledge.

With respect to the above concerns, specifically at times of additional hazardous health distresses, faculty have to take into consideration multiple factors in designing assessment that employs various types of questions, depending on the module, the level of learners and mode of delivery. While objective questions are needed in some modules for online exams that are timed by one or two hours, Take Home Exams to require different kinds of questions since the time here could be a couple of days. Here the questions should not be straightforward where students can locate the answer in the prescribed textbook. Rather the questions should test critical thinking aspects, which can be accomplished through asking analysis, synthesis, comparison and contrast questions, etc. Qashoa (2013) and Al-Zahrani \& Al-Bargi (2017) argued that multiple-choice, fill-in-the-blank, or matching formats could be used to assess content that is retrieved through remembering terms or understanding concepts (Amatari, 2015; Vebriyanto, 2015). Whereas higher tiers of analysis or synthesis require different types of assessment and maybe better applied in taking Home Exams (Champakaew \& Pencingkarn, 2014). The studies and debates continue to inform academic pursuit in terms of appropriate modes of assessment during the lockdown.

In the above literature, concerns over the ability of faculty to adapt and ensure students succeed in a suddenly changing world are raised. The surveyed literature indicates that educational institutions must perform a more reflective diagnosis to inform the teaching and learning experiences in unpredictable situations and propose working scenarios.

\section{Objectives of the study and study questions}

This study attempts to reflect on the impact of the pandemic on EFL teaching and learning practices in the different branches of the $\mathrm{AOU}$ and assess the effectiveness of the adopted procedures from the perspective of English language instructors and learners. The study reports on AOU efforts during the Covid-19 crisis and investigates its capability to adapt and sustain good quality EFL 
education while operating under dire circumstances and lockdown. In particular, the study seeks answers to the following questions:

1. How did online teaching and learning take place, and how does it compare with face-to-face situations?

2. What were the different types of online learning? And were students motivated and engaged in an online environment?

3. What were the challenges related to online learning?

4. How were English language instructors engaged in teaching foundation modules, able to adapt and adapt teaching methods felicitous for online teaching, and how similar or different were these methods from the traditional face-to-face ones?

5. How effective are these methods as reflected in students' performance in exams?

6. How do students evaluate online teaching in terms of teaching quality, interaction with their teachers, assessments, reliability of the technology associated with online teaching and use of online support forums?

7. What implications would this study have in the area of teacher training, textbook writing and assessment preparation?

\section{Methodology}

\subsection{Data collection}

In order to carry out the study, the authors applied the following methods of data collection:

1. The study involved seeking feedback, through a survey, from randomly selected EFL instructors from the nine AOU branches: Saudi Arabia, Egypt, Jordan, Lebanon, Bahrain, Oman, Palestine and Sudan (42 instructors.) The survey comprised questions that elicit information about EFL instructors' views regarding online teaching, their teaching methods, the way assessments are prepared and their effectiveness in measuring student progress, grading, etc. (See Appendix 1).

2. An anonymous student survey that reflects learners' attitude toward online teaching, the academic and technical strengths and drawbacks associated with it and how the shortcomings were tackled, their opinion regarding assessments, class interaction, etc. The random sample comprised 911 students. (See Appendix 2).

3. Analysis of a random sample of Take-Home Exams to see how such exams measure attainment in language skills and the reliability of the methods utilized in conducting these exams.

Comparing learners' performance in on-campus final exams and finally take-home assessments based on the spring $2020-2021$ semester results.

\subsection{Participants and Surveys}

Participants in the study are as follows:

1. Forty-two (42) randomly selected English skills Instructors from the above-listed branches of the AOU responded to a survey that elicited their views on online teaching methods, assessment and grading. Their responses were analyzed and grouped into certain categories highlighted in the discussion section.

2. More than 1000 randomly approached students registered in the zero-credit English communication skills courses $(n=4116)$ and credit-based English communication skills courses EL111 and EL112 $(n=7552)$ at the time when the study was conducted. The randomly targeted students were asked to respond to a survey designed on Microsoft Forms and presented in both English and Arabic to ensure adequate feedback from students with lower proficiency in English. Overall, 911 responses were collected from AOU branches during the summer of 2021. Students in the study were enrolled in one of three courses: EL099, EL111 and EL112, which correspond to the last three levels of the orientation programme at the AOU. 
Charts (1)
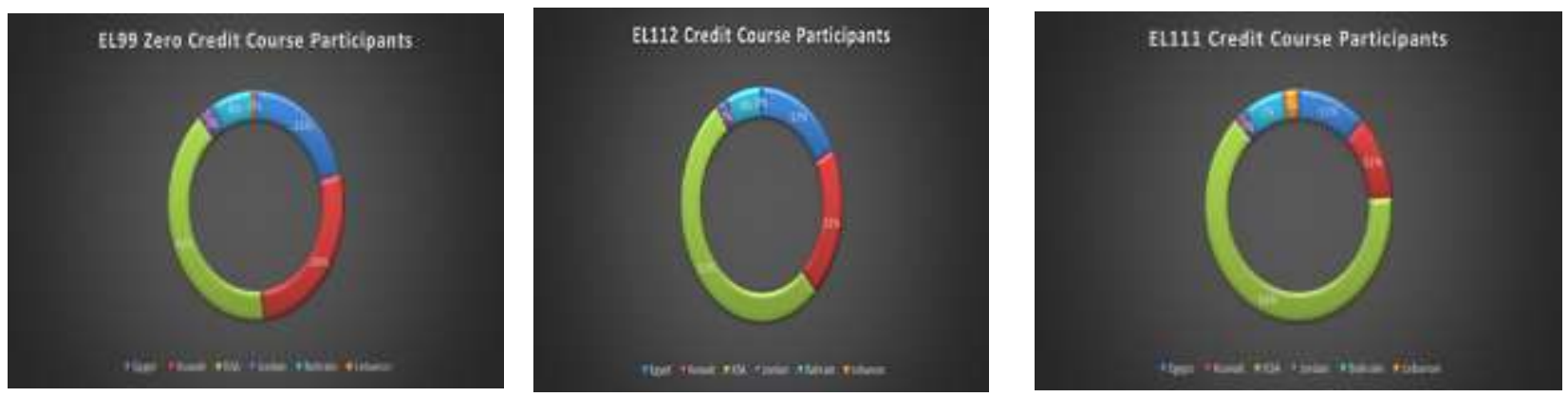

In the survey, students were asked to rate 26 statements according to a 5-point Likert scale to provide information on preferences (positive/negative), the intensity of opinion, and a neutral point without overwhelming the respondents: $(1=$ Strongly disagree, $2=$ Disagree, $3=$ Neutral, $4=$ Agree, $5=$ Strongly agree). The statements were designed to elicit feedback on factors impacting EFL teaching and learning during the Covid-19 pandemic. The statements fall under four broad categories:

1. External factors,

2. Interactivity during class,

3. Quizzes, final exams, and

4. Students' general attitudes towards face-to-face and/or online learning and teaching.

\section{Analysis of the results:}

As indicated above, the study explores the impact of the Covid-19 pandemic on English foreign language teaching and learning practices across AOU branches and assesses the effectiveness of the adopted procedures from the perspective of faculty and students.

\subsection{Analysis of the instructors' Survey}

The study involved seeking feedback from forty-two English language skills instructors, randomly selected from several AOU branches that participated in the study. They were given a survey to respond to (see Appendix 1), which elicited their reflection on teaching and learning English during Covid-19 in the academic year 2020/2021.

In responding to "How did online teaching and learning take place and how does it compare with face-to-face situations?", instructors reported that in the academic year 2020/2021, the teaching was conducted online in Bahrain, Lebanon, KSA, Oman, and Kuwait while it was conducted both online and on-campus in Egypt. When asked about the "similarities and differences between the teaching methods utilized virtually as compared to traditional face-to-face ones," sixty-seven per cent (67\%) of the instructors in the participating branches stated that there were differences between the two modes. Eighty per cent (80\%) of the instructors from Bahrain and KSA, seventy-eight per cent (78\%) from Egypt, forty-five per cent (45\%) from Kuwait, forty per cent (40\%) from Oman, and fifty per cent (50\%) from Lebanon reported that there were differences in the teaching skills required in implementing online teaching as compared with face-to-face one, the teaching methods, procedures and activities used, as well as students' motivation and engagement. Some additional comments were provided in the survey, as in eth below:

- Face-to-face teaching depends significantly on body language and facial expressions, either to explain the material taught or to gauge students' understanding and their level of participation. In a virtual learning environment, that element of direct communication is lost; both students and instructors rely mostly on sound or verbalizing their understanding, and students do not always share their thoughts.

- In the traditional classroom, instructors rely a great deal on using whiteboards and books, which had a huge impact on students' grasp of the taught material as they could take notes, do exercises in their own books, etc. In the virtual classroom, this element and level of engagement are completely lost.

- Monitoring students is much more difficult in online teaching than in face-to-face schooling.

- $\quad$ Students felt disconnected from the classroom environment. 
- Many in-class activities, such as pair work, group work, etc., became difficult to conduct through the online platform and thus, student participation was very low.

Charts (2)

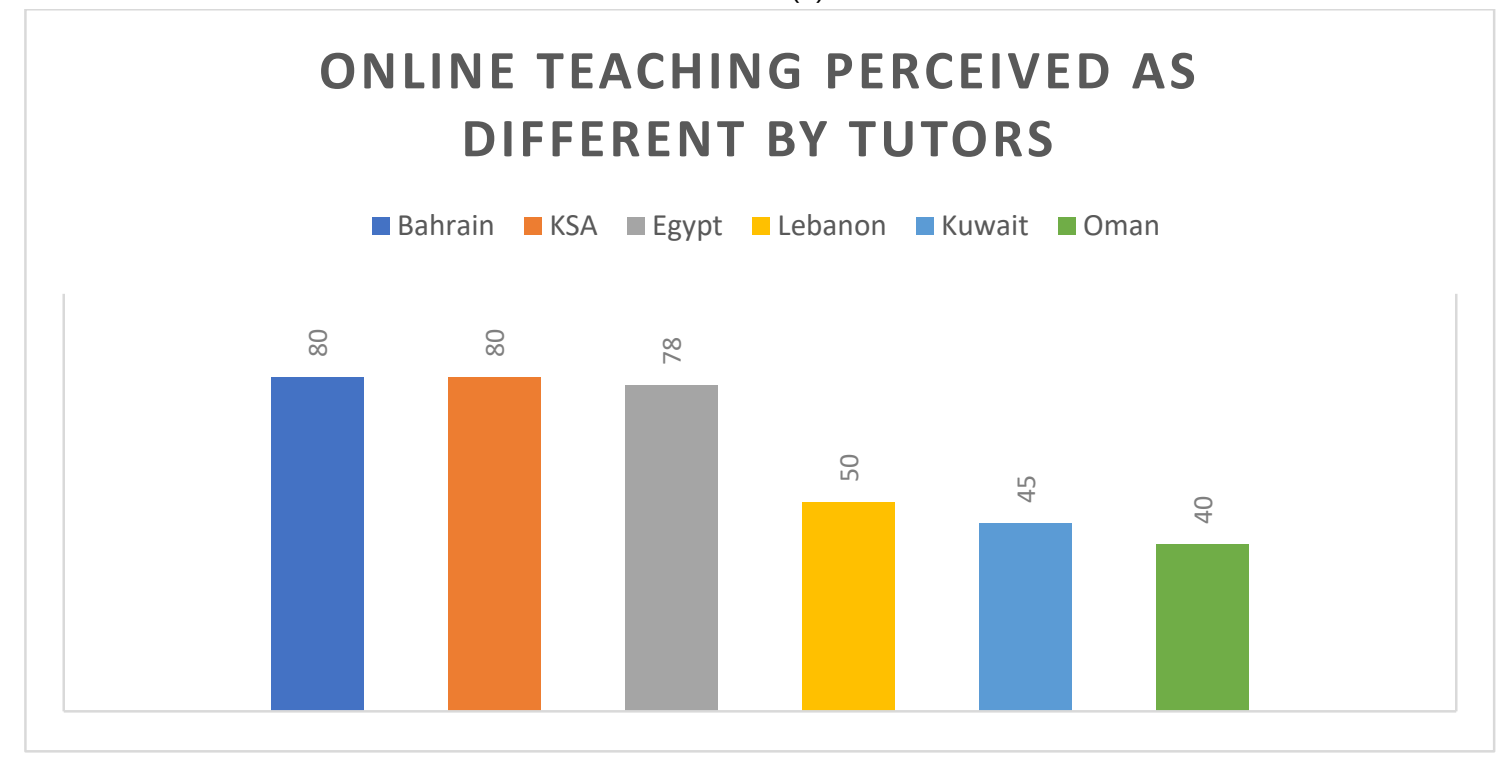

Despite the dissimilarities enunciated by this instructor, a good percentage of the surveyed instructors focused more on the similarities than the differences between the two types of teaching. The survey findings show that sixty per cent (60\%) from Oman, fifty-five per cent (55\%) from Kuwait, fifty per cent (50\%) from Lebanon, twenty-two per cent (22\%) from Egypt, and twenty per cent (20\%) from Bahrain and KSA reported that there were similarities between the two modes.

Chart (3)

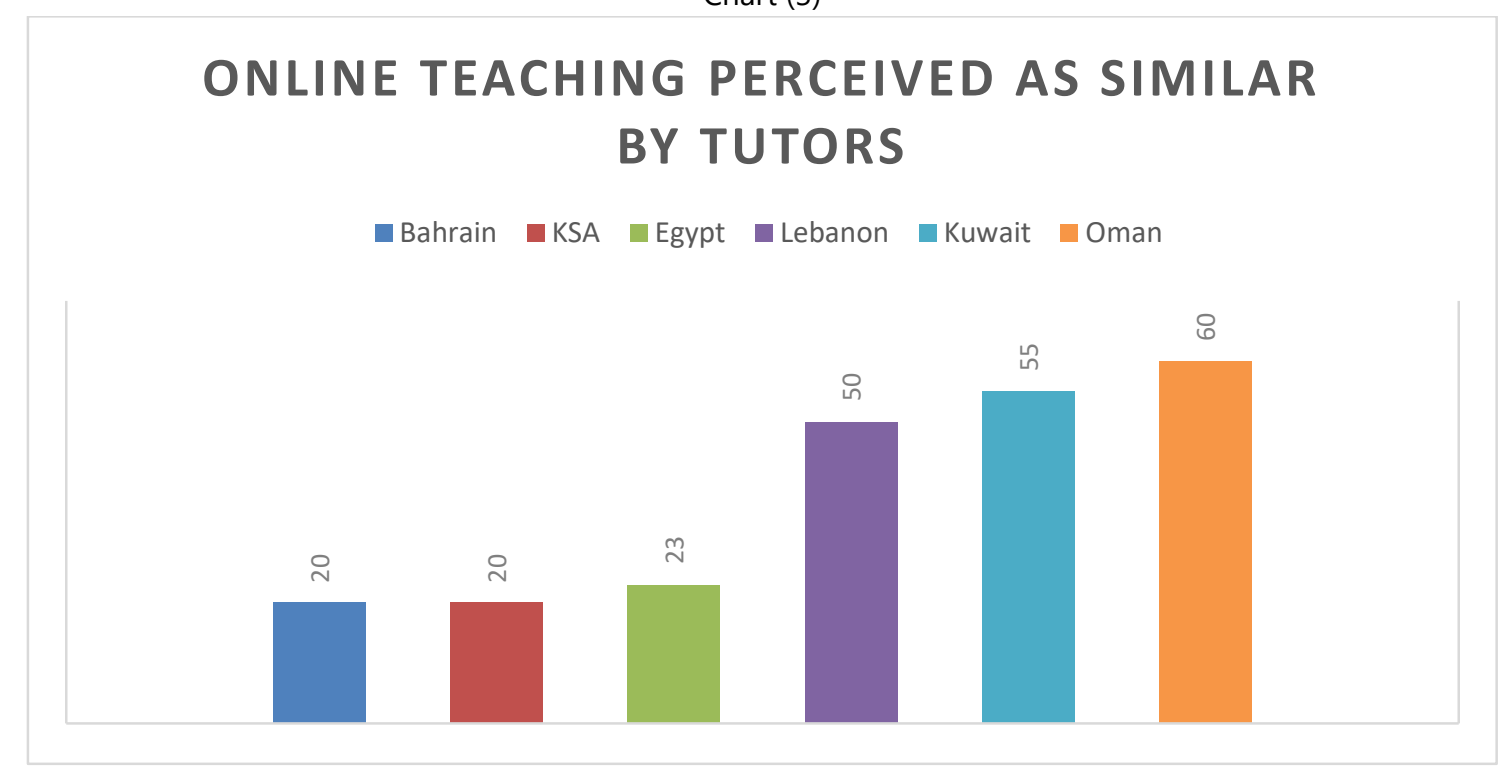

Similarities include the use of PowerPoints presentations, game-based learning, one-to-one discussion, open and closed discussion, personalized learning, direct instructions, and inquiry-based learning, in addition to assigning HW and giving and receiving feedback. An instructor from Kuwait Branch added that in the two modes, instructors "used the same curriculum, addressed the students' needs individually, and created a positive learning environment."

In responding to question 2 on the different types of online learning, instructors reported using various teaching methods and tools that engage various types of students with different learning styles. For example, they mentioned interactive online exercises, 
discussions, presentations, audio and videos clips, Google images, guessing games, online writing workshops, game-based teaching, problem-based learning projects, mind mapping, flipped classroom, in-class projects, quizzes, and blogs. In addition to the innovative and student-centred teaching methods, the respondents commented that they made use of many effective online platforms, tools and websites which offered their learners a wide range of learning experiences such as Zoom, MS Teams, Poll everywhere, British Council site, garneteducation.com, Nearpod, Thinkific, Khan Academy, in addition to watching YouTube videos and creating What's App groups. Virtually all instructors agreed that these methods, platforms and tools have motivated their students and empowered them.

In their responses to "how successful the online methods followed in engaging students in communication skills courses," instructors gave various responses. In both KSA and Kuwait, the largest two branches, $80 \%$ of the tutors stated that the online teaching methods were successful as they enabled instructors to create an effective learning community, deliver complex information in an interesting manner, make classes more engaging, and give them the chance to review homework and provide feedback. Instructors also added that the online teaching methods augmented the students' level of engagement, which differed depending on the students' level of computer literacy and the topic under discussion. Twenty per cent (20\%) of the KSA and Kuwait instructors, however, reported that not all the students were able to be engaged properly. A very similar percentage, seventy-five (75\%), agreed that the online teaching methods were moderately successful in Egypt. Twenty-five per cent (25\%) mentioned that communication with the learners was very weak either due to weak internet speed or learners' refusing to unmute, which, according to this marginal percentage of instructors, compelled them to resort to "one-sided lecturing".

The positive attitude towards the teaching methods used in the online mode of teaching was also reflected in the Lebanon Branch instructors' responses. Seventy-five per cent (75\%) thought that the online teaching methods were successful to a certain extent judging from the participation rate and students' discussions either in writing in the chat section or through oral interaction with the instructors and peer learners, while twenty-five per cent (25\%) of Lebanon instructors stated that communication skills courses needed more face-to-face interaction in class. In Bahrain and Oman, sixty (60\%) of the instructors stated that online teaching methods were very successful, and the success was reflected in the percentage of students' attendance, punctuality, and tests results. On the other hand, forty per cent (40\%) of the instructors did not agree, indicating that not all learners were able to fully participate due to some technical problems or weakness in their speaking skills.

Charts (4)

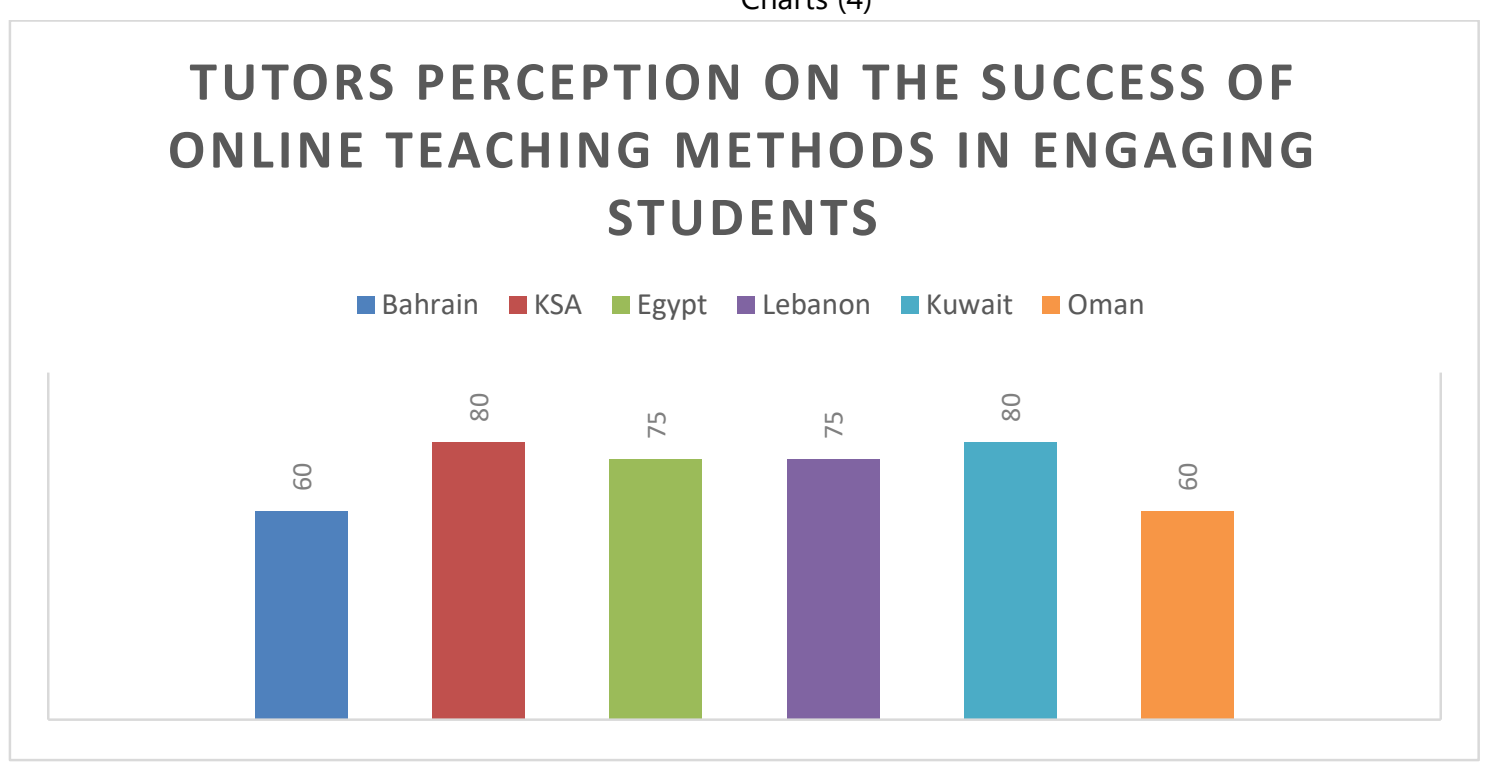

On the learners' side, when instructors were asked about "the learners' perception of the virtual teaching methods," they reported that their learners perceived the virtual methods differently. In Oman, seventy per cent (70\%) of the instructors mentioned that virtual methods were perceived well, and their learners were delighted with the online activities and games that instructors implemented. Thirty per cent (30\%) stated that at the beginning, the learners were not satisfied but gradually got used to them and started enjoying the change and the new approach of learning. In Bahrain and Lebanon, sixty per cent (60\%) commented that their learners - who can be described as digital natives - enjoyed the virtual experience due to the availability of the recorded lectures, convenience, especially for the working students, and the ability to attend their classes from anywhere, but forty per cent (40\%) of the instructors mentioned that their learners encountered some technical difficulties at the first few classes. An instructor from the Lebanon branch stated, "In advanced courses where fluency in the language and learner independence are common, the 
satisfaction was higher." Similar to Bahrain and Lebanon, in Egypt, fifty-six per cent (56\%) of the instructors stated that their learners had a positive reaction to the virtual learning, especially the shy students who used the chatbox to communicate their thoughts, participate in meaningful discussions, contribute to conversations, and voice their opinions. They also commented that the online classes helped the shy students feel more comfortable. However, twenty-two percent (22\%) of the instructors in the same branch shared the students' dissatisfaction as some of them had difficulty in dealing with online platforms while others disliked online assessments. In addition, the rest of the instructors, twenty-two per cent (22\%), expressed the students' ambivalent and mixed feelings between accepting and rejecting the virtual learning. In both KSA and Kuwait, most instructors (90\%) pointed out that their learners were in favour of the virtual learning mode, with some indicating that in the beginning, their learners preferred the traditional method, but gradually they got used to the virtual methods and developed intimacy toward it.

Charts (5)

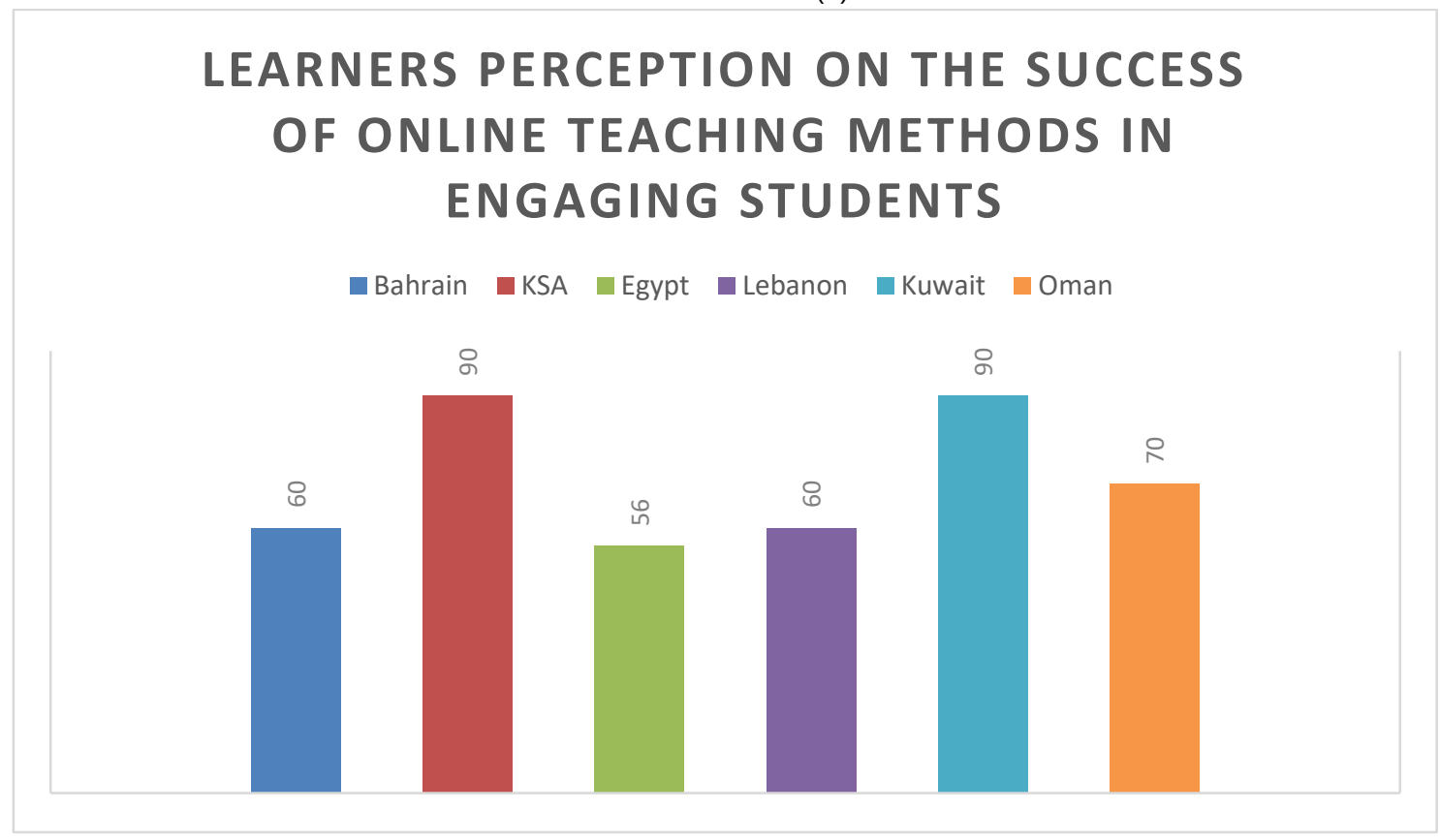

The instructors' stance toward the "effectiveness of the methods used virtually as reflected in students' performance in assessments" was quite positive, too, despite a reasonable percentage of disagreement in instructors' views. In Bahrain, all the respondents agreed that the student's grades in TMA (Tutor Marked Assignment), MTA (Midterm Assessment) and (THE) Take Home Exams to reflect the effectiveness of such methods. In a similar vein, in KSA, ninety per cent (90\%) of the instructors stated that virtual methods were very effective and enabled students to achieve good performance in the quizzes and final exams. In Lebanon, seventy-five per cent (75\%) of the instructors have testified that these methods were quite effective as a great number of the students achieved well in assessments, while $25 \%$ disagreed as the students' grades were similar to those in previous years. In Kuwait, only half of the instructors mentioned that virtual methods were successful in measuring and identifying students' weaknesses. In Egypt, forty-four per cent (44\%) only were satisfied with the student's performance in different types of assessments while twenty-two per cent (22\%) were neutral in their responses and thought that the virtual methods were successful to some extent, and thirty-four per cent (34\%) of Egypt instructors gave undecided responses. In Oman, forty per cent (40\%) stated that these techniques were quite effective in helping students perform well in the different types of assessments, while twenty per cent (20\%) stated that in-class assessments were effective. $40 \%$ of instructors from the Oman Branch were not completely satisfied with online assessments, partially due to connectivity issues.

In addition to the effectiveness of the teaching methods as reflected on learners' performance in assessments, the instructors were asked to "compare the students' attendance in on-campus to online sessions." Instructors from Bahrain, Egypt and KSA reported that the percentage of students' attendance in online classes was relatively higher than in on-campus sessions, which was a result of the periodic interaction with their learners via email, LMS, chat forums, etc. The percentages of higher comparison in online attendance in the three branches are $69 \%, 68 \%$, and 58 respectively. In the other three branches, Kuwait, Oman, and Lebanon, instructors reported that no big difference could be observed.

Finally, in their responses to "How effective are these methods as reflected in students' performance in exams," eighty-eight per cent (88\%) of instructors from Egypt and Bahrain, sixty per cent (60\%) from KSA and Oman, fifty-five (55\%) from Kuwait, and fifty

Page | 51 
(50\%) from Lebanon reported that these methods were effective, as reflected in students' performance in exams. However, for some instructors, students' accessing the Internet during Take Home Exams (THEs) remained a major concern, despite the fact that exams were tailored in such a way that the Internet would not be of much help. In THEs, students would be asked, for example, to summarize a provided article, write on a topic that does not exist on Google, analyze a text, etc.

Generally, in analyzing instructors' attitudes toward online assessments, almost $60 \%$ are satisfied that assessments are both reliable in terms of consistency of scores and valid in terms of testing the intended language skills and that students' performance, given all the administrative measures utilized to guarantee students' reliance on themselves, is satisfying. The other $40 \%$ of the instructors surveyed are not quite satisfied with the online assessments as they think that students may seek the help of the net as well as other dishonest means. The instructors who did not feel completely satisfied with online assessments are fifty per cent (50\%) from Lebanon, forty-five per cent (45\%) from Kuwait, forty per cent (40\%) from KSA and Oman, and twenty-two per cent from Egypt and Bahrain.

The effectiveness of the virtual methods in assessing the learners' performance was compared to students' achievement in previous years.

Charts (6)

\section{TUTORS' SATISFACTION WITH THE EFFECTIVENESS OF ONLINE METHODS IN REFLECTING LEARNERS' PERFORMANCE}

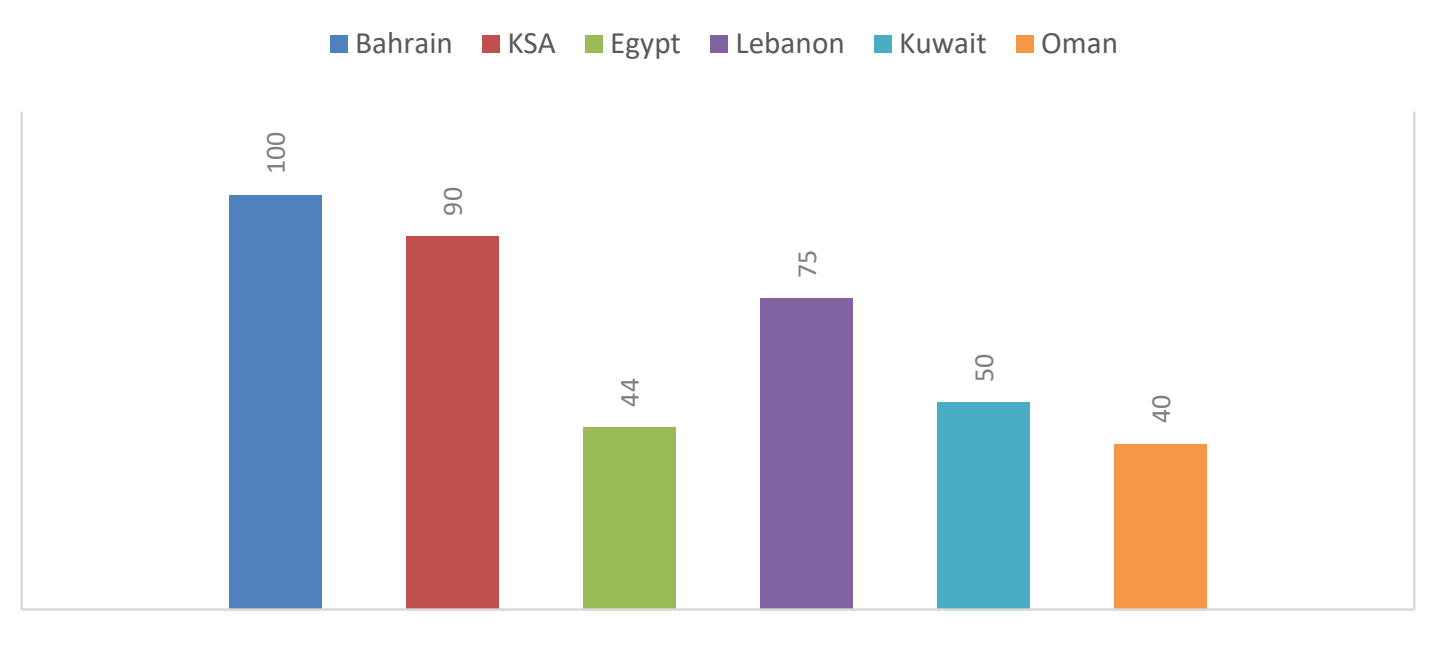

In Bahrain, all tutors (100\%) agreed that the student's grades in TMA, MTA and Take Home Exams (THE) reflect the effectiveness of such methods. In Egypt, 44\% of the tutors were satisfied with the student's performance in different types of assessments, while $22 \%$ were neutral in their responses and thought that the virtual methods were successful to some extent. 34\% of Egyptian tutors gave vague responses. In KSA, 90\% of the tutors stated that virtual methods were very effective and enabled students to achieve good performance in the quizzes and final exams. In Kuwait, $50 \%$ of the tutors mentioned that virtual methods accurately measured and identified students' weaknesses. In Oman, 40\% of the tutors stated that these techniques were quite effective in helping students perform well in the different types of assessments, while $20 \%$ stated that in-class assessments were effective, but in the other types of assessments, the virtual methods were not very effective. The rest of Oman tutors had negative views about the online assessments. Finally, in Lebanon, $75 \%$ of the tutors have testified that these methods were quite effective as a great number of the students achieved well in assessments, while $25 \%$ disagreed as the students' grades were similar to those in previous years. 
Chart (7)

\section{TUTORS' SATISFACTION WITH ONLINE ASSESSMENT}

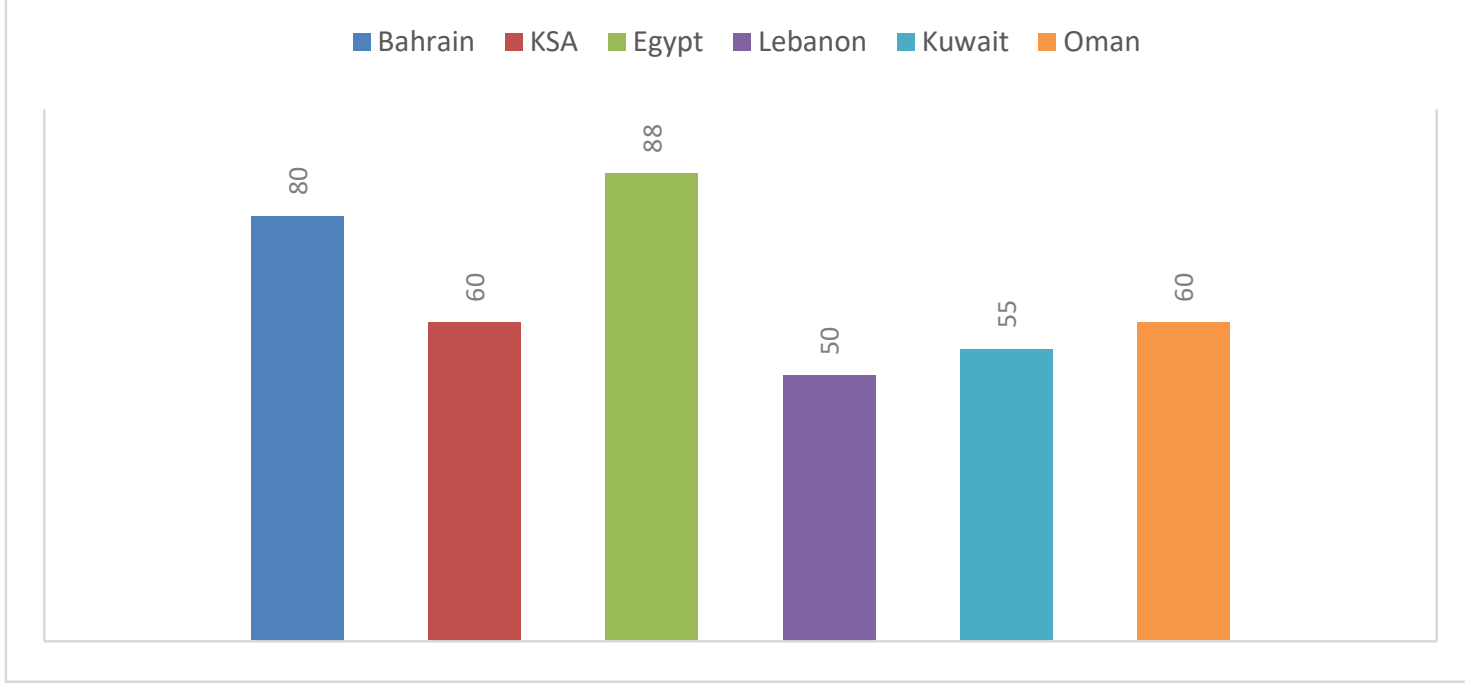

\subsection{Analysis of Student Survey}

As indicated in the methodology section, students across the participating AOU branches were surveyed to gauge their feedback on in-class and off-class learning aspects. The survey statements were designed to elicit feedback on internal and external factors influencing EFL teaching and learning during the Covid-19 pandemic.

Students were enrolled in one of three courses: EL099, EL111 and EL112, which correspond to the last three levels of the orientation programme at the AOU. In the demographic profiling of our participants, following St. Amour's study (2020), our student survey confirmed that about $57 \%$ of the respondents were female and $43 \%$ male students. Besides, about a third of the students (27\%) had taken an on-campus, face-to-face ELU course prior to the Covid-19 restrictions, while the rest (73\%) enrolled during and after these restrictions were in place, and hence had mostly studied via online classes (see Appendix 2 ). The following graph shows the number of participants from each branch of the AOU.

Chart (8)

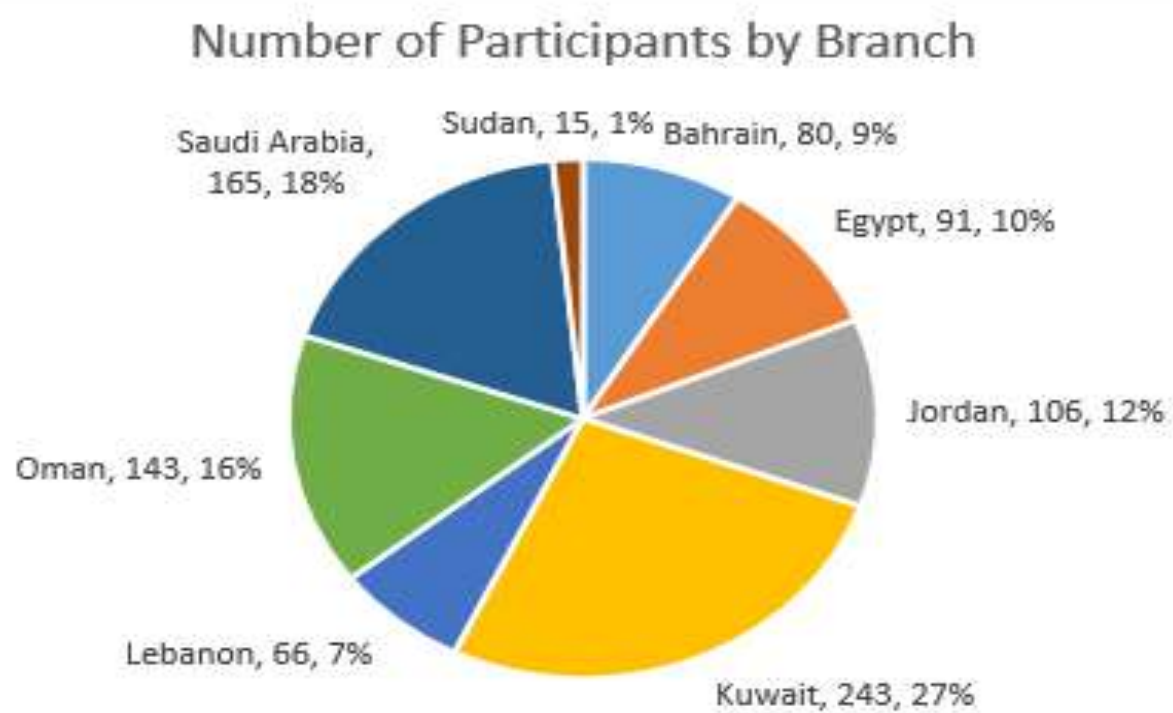


Chart (9)

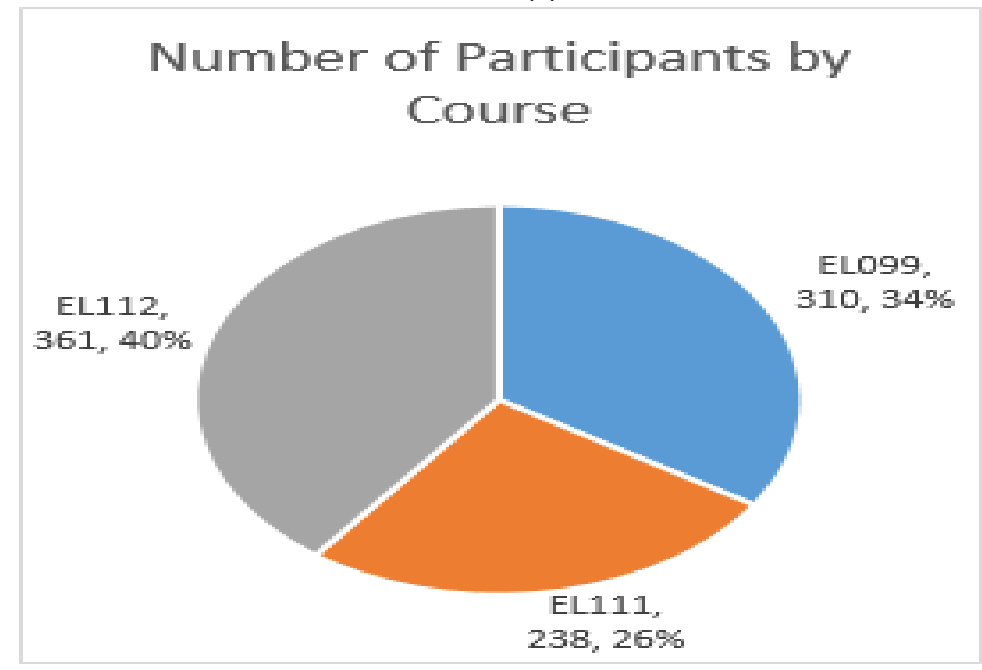

Chart (10)

Number of Participants by Gender

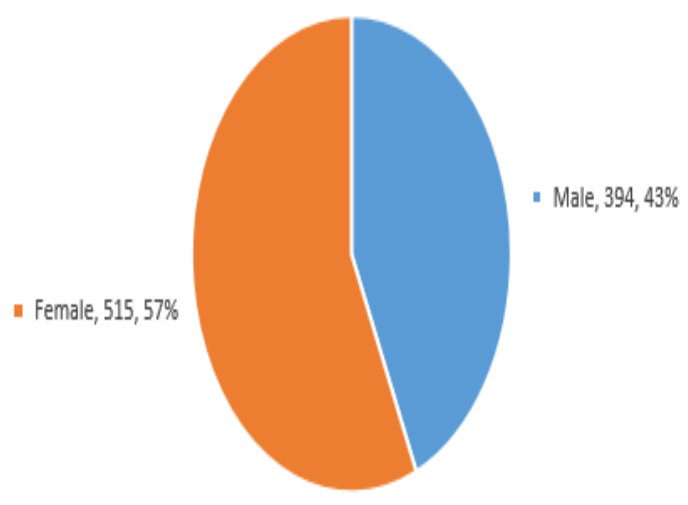

\subsubsection{External Factors}

The availability and reliability of both electricity and the Internet were common concerns among students. In response to the question on "The quality of the Internet was the main challenge in my online studying", one-fifth of the respondents (21\%) strongly agreed, and almost a third agreed (28.4\%), while (23.3\%) were neutral. Electricity was another mentioned obstacle. However, (58.29\%) disagreed or strongly disagreed that (Electricity was not always available in my area), while (13.83\%) agreed and (19.87\%) were neutral. A closer look by filtering for responses from specific countries reveals an opposite view. Two-thirds (66.67\%) of students in Lebanon agreed or strongly agreed with this statement, as the following graph shows, owing to the predominantly power outage in the country at the time of the study. This finding corresponds to the Online Education Trends Report (OETR) (2021: 14) in confirming problems associated with access to technology or internet connectivity and underlining it as a main challenge reported by the students. 
Chart (11)

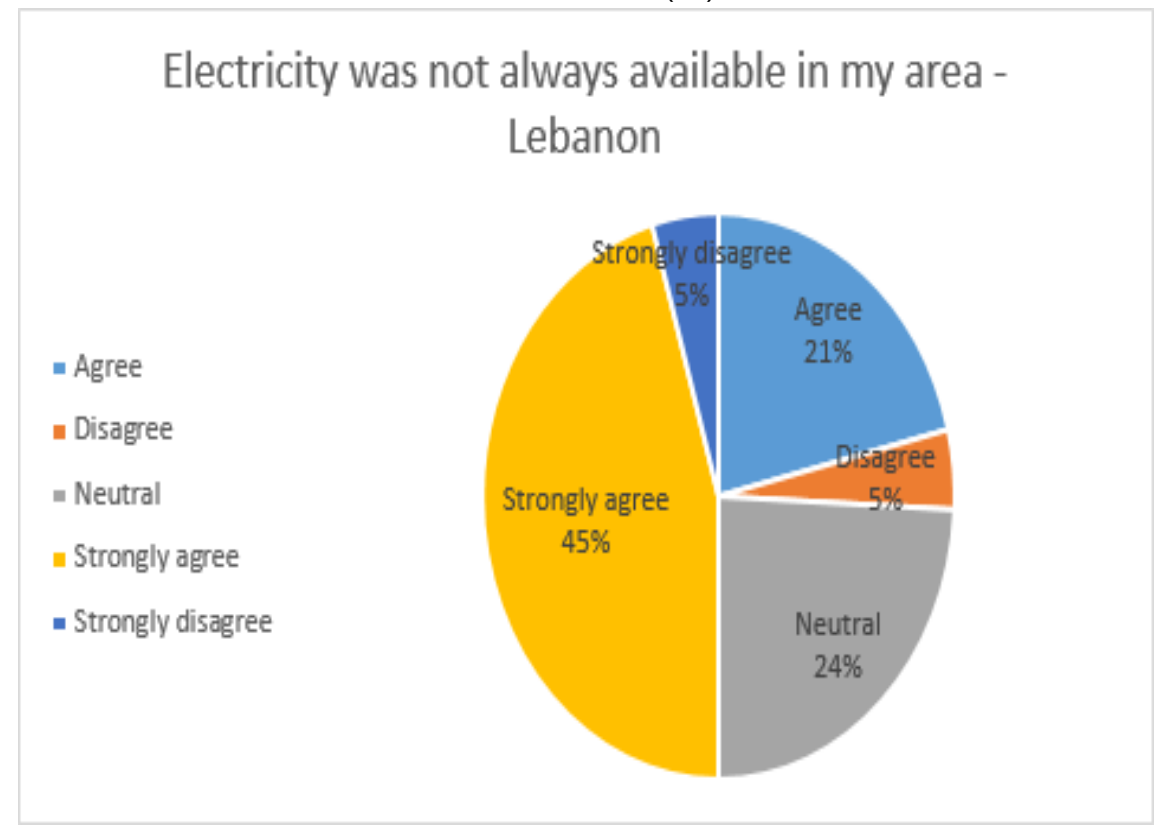

Electricity and the Internet have had other effects on learners and teachers' behaviour. Overall, (22.72\%) agreed and (10.21\%) strongly agreed that (Sometimes the quality of the teacher's voice was unclear), while the majority (25.91\% and $18.44 \%)$ either disagreed or strongly disagreed respectively. In response to the statement (Sometimes the teachers asked students not to use their cameras and just listen to lessen the load of the Internet), a quarter agreed or was neutral (25.36\% and 26.13\%), respectively. A third of the students either disagreed or strongly disagreed (19.76\% and $15.70 \%)$, respectively. The agreement was slightly higher for students from Egypt, Lebanon and Sudan. These three branches reported a higher impact of external factors like power cuts on the online teaching and learning process.

Finally, results were varied for the (One of the difficulties of online learning is that we are more than one at home and we have one computer only). A quarter (25.03\%) strongly disagreed, (22.17\%) disagreed, (20.42\%) were neutral, (14.05\%) strongly agreed, and (18.33\%) agreed. The agreement was noticeably higher among students in the Kingdom of Saudi Arabia (26.06\% strongly agreed, and $18.79 \%$ agreed). This response contributes to alerting researchers to the intervention of external factors in any evaluation of online teaching and learning in the third world context.

Chart (12)

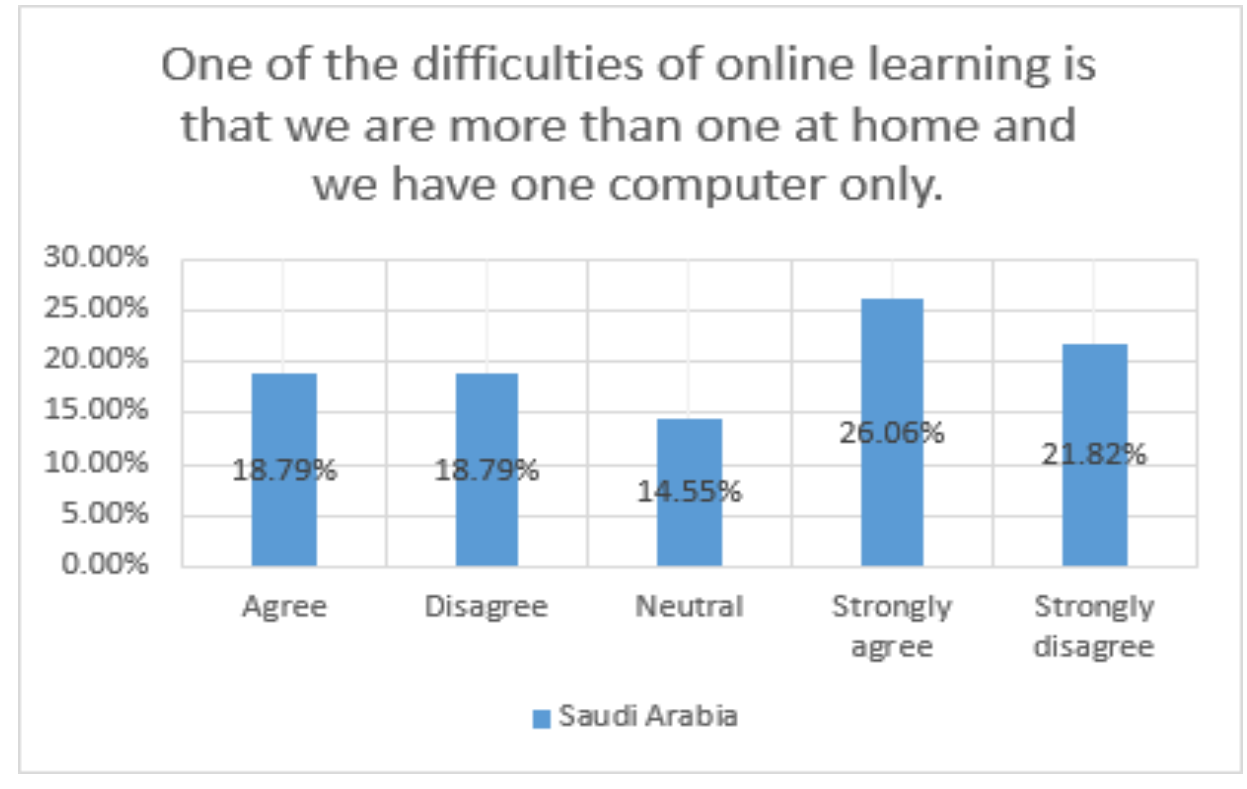




\subsubsection{Interactivity during class}

In response to student opinion on rating with satisfaction the amount of interactivity in online sessions, one-third of the respondents strongly agreed or agreed to the statement, "During online session time, the teacher presents, and students are mostly silent", and (28.98\%) were neutral. On the other hand, a third (25.69\%) disagreed, and (15.59\%) strongly disagreed. Male students had a higher agreement rate than female students. This finding can have an impact on future gender studies on perceptions of teaching and learning.

As for student feedback on group work, less than one third agreed or strongly agreed with the statement, "In online teaching, group work was impossible". Whereas (29.97\%) disagreed and (11.75\%) strongly disagreed, while (23.27\%) were neutral. As for spoken interaction, a third (32.49\%) were neutral towards the statement, "one of the disadvantages in online teaching is that spoken interaction is minimized", while somewhat equal numbers: $(21.41 \%)$ agreed and (19.21\%) disagreed. For a similar statement on feedback, "In online teaching, teachers do not correct my grammar or pronunciation when I answer questions or give a short presentation", the majority (32.71\%, 298 students) disagreed and (26.34\%, 240 students) strongly disagreed which indicates active and immediate feedback from tutors during online classes across all branches. This finding conforms to the results obtained by Online Education Trends Report (OETR) (2021: 44) on students reporting positive views about online learning.

\subsubsection{Quizzes and Final Exams}

Students' opinion was equally divided, and feedback on quizzes and final exam did not provide a decisive preference in agreeing or disagreeing with the statement that "Quizzes are better conducted online than in face to face teaching", which indicate that assessment in the on-campus or online modes is perceived to be equally demanding from students' perspective.

Chart (13)

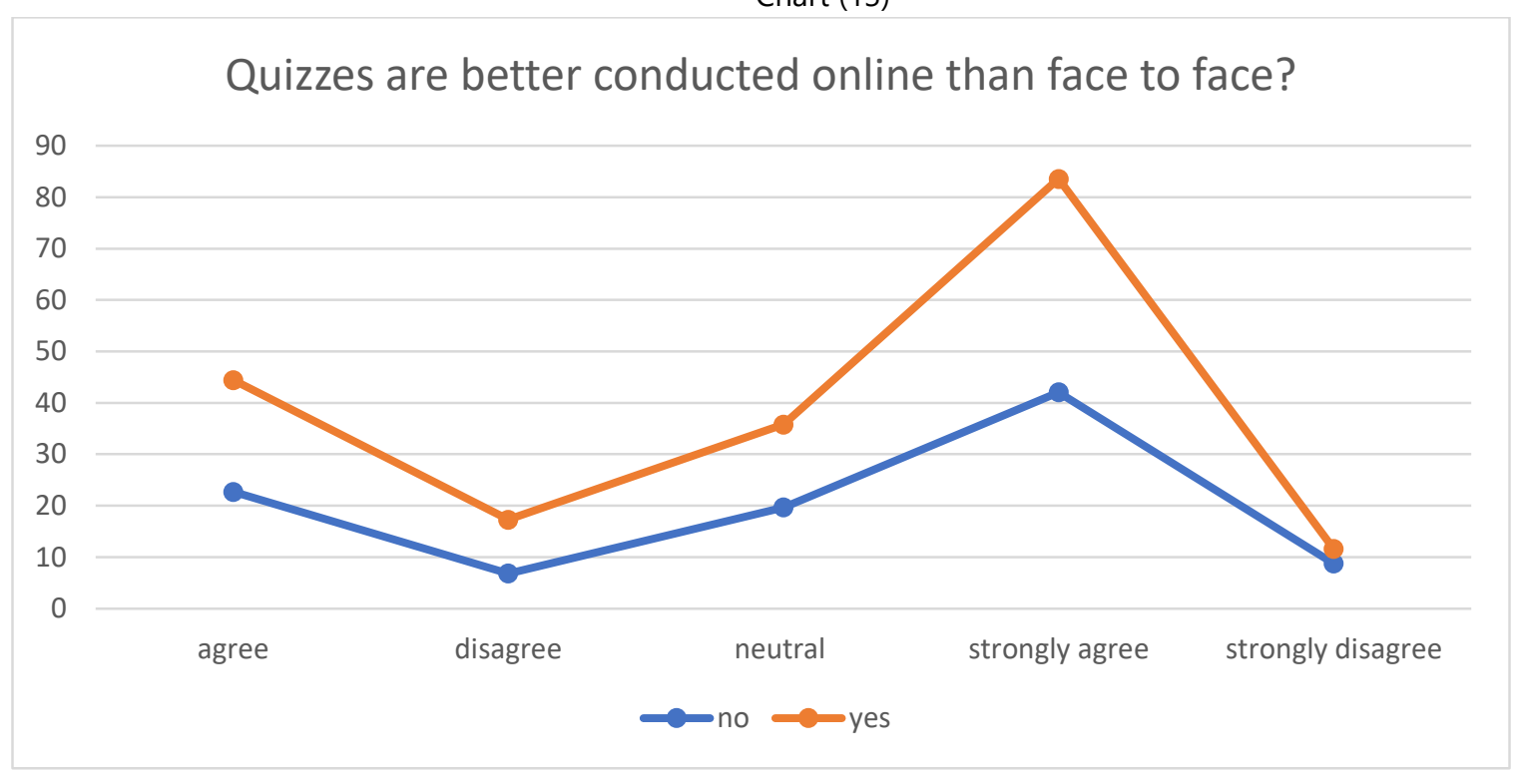

Over half of the students agreed or strongly agreed that their teachers provided feedback after exams (36.55\% and $20.20 \%$ ), respectively, while (25.47\%) were neutral. No significant differences were found among students who had face-to-face classes prior to the lockdown restrictions and their counterparts. There were four items that presented various aspects of academic integrity. Two-thirds of students agreed or strongly agreed that "When doing quizzes, we were warned not to share answers with anyone": (37.21\% and 37.32\%) respectively; about (16\%) remained neutral while less than (10\%) disagreed. In the cross-checking students' replies with tutors' feedback and checking a random sample of take-home exams to see how such exams measure attainment in language skills and the reliability of the methods utilized in conducting these exams. Findings revealed that the exam questions themselves were written for higher-order skills so that the Internet could not provide direct, identical answers. They included asking students to provide further arguments to support or refute a specific point of view, to paraphrase or provide alternative interpretations. Most students agree that "In final exams, they never used Google because the questions were tailored in such a way that the Internet could not help": (34.47\% and 31.39\%) respectively, while (22.28\%) were neutral.

Most students agreed (69.59\%) that, "In final exams, they never used Google because tutors made it clear that if they found answers from the Internet, the student would get a zero". Finally, in practice, on the question of whether students use the Internet to get 
their answers, "I use the Internet to get answers for my quizzes and exams", most students in anonymous replies say they did not (62.79\%). Most students agreed or strongly agreed (37.54\% and 26.56\%), respectively, that, "Our teachers' style of teaching prepared me for the Final Take-Home Exams". A quarter (24.26\%) were neutral, while (6.48\%) disagreed and (5.16\%) strongly disagreed. Among students who had both modes of study, students who have had both experiences (face-to-face and online learning) expressed higher rates of agreement with the statement "Final Take-Home Exams (FTHEs) are as challenging as on-campus exams): almost two thirds (31.85\% agreed, and $30.24 \%$ strongly disagreed".

On the question of "How satisfied were students with their grades" most students were neutral (39.41\%) towards the statement, "My marks in exams are higher than my marks in face-to-face learning", which indicate no significant inclination. Interestingly, students who experienced both modes and who are in a better position to judge also did not express significant higher rates of agreement (18.15\% agreed, and $19.76 \%$ strongly agreed). This indicates that students perceived online and on-campus exams of the same difficulty level.

\subsubsection{General attitudes towards face-to-face vs Online learning}

Overall, students had positive impressions about online learning (half to two thirds) and slightly similar or higher in students who have had face-to-face, on-campus classes before. In response to the statement "I think I learned through online teaching more than I learned through face-to-face mode", about half of the respondents agreed (22.39\% agreed, and $27.77 \%$ strongly agreed), while (24.26\%) were neutral, and a quarter disagreed (10.43\% disagreed, and $15.15 \%$ strongly disagreed). Two-thirds of students agreed that "Studying online made me participate although I am usually shy", and the same rates were expressed by students who went through both modes of study (26.21\% agreed, and $32.05 \%$ strongly agreed). Most students expressed their motivation for selflearning in response to the statement (Studying online motivated me to use the Internet more than before to learn by myself): (31.38\% agreed, and $36.55 \%$ strongly agreed). Overall, about $60 \%$ agreed that "Online teaching turned out to be better than I expected). Moreover, both categories of students expressed similar agreement rates with the statement "I benefited from the help my teachers extended to me during their online office hours", student whose first orientation courses were online expressed (31.92\% agreed, and $17.7 \%$ strongly agreed), while students who experienced both modes were significantly higher ( $31.85 \%$ agreed, and $27.42 \%$ strongly agreed). About a third were neutral in both categories.

\subsubsection{Digital Writing Centre and English Speaking Skills Centre}

Writing Centers, run by faculty members from the English programs in response to the Covid-19 lockdowns, were changed to online forums. In response to the statement: "Changing the Writing Center and the English Speaking Skills Center into online forums has been helpful", students' feedback provided more than $50 \%$ rates of agreement (30.69\% agreed, and $21.34 \%$ strongly agreed). Branches with expressed problems of connectivity and power outage contributed to rating on neutrality (34.67\%), more favourable views came from students in Kuwait, Oman, Egypt and Bahrain, probably owing to students' intensive use of the Digital Writing Center in these branches.

\subsection{Comparing the results of English Communication Skills modules before and during lockdown}

The final informing measure concerned the results of English Communication Skills modules during spring 2019-2020 and spring 2018-2019 which was conducted to find indications of change in course grades that would reflect changes in student performance. The authors compared the pass ratio of English Communication Skills courses between spring 2019-2020 and spring 2018-2019.

Chart (14)

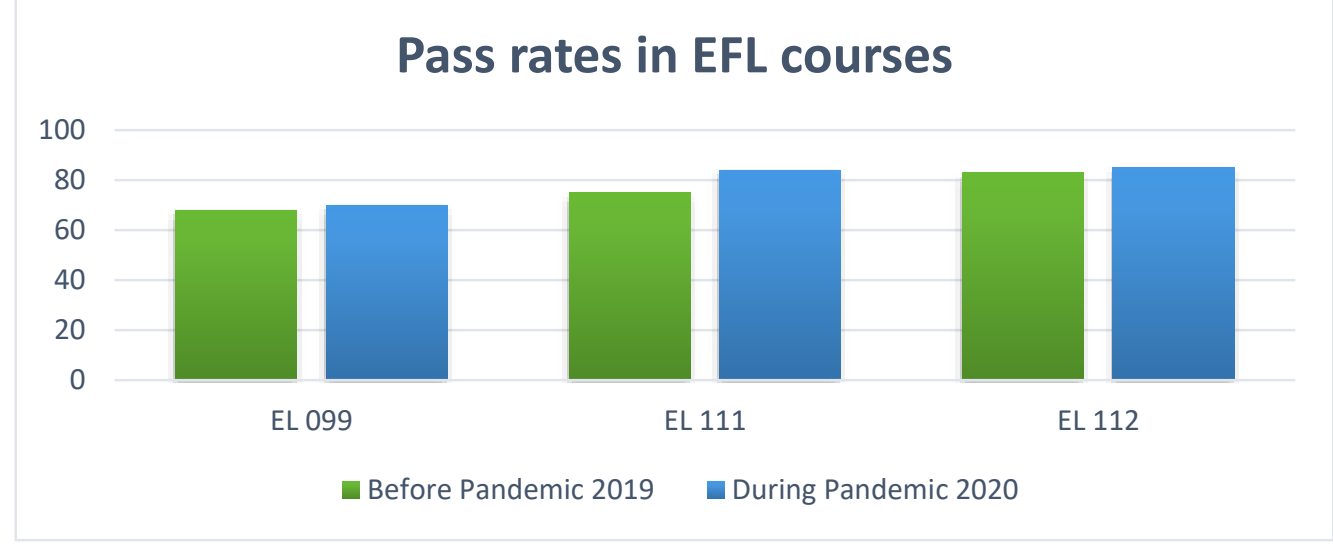


Grade difference in EL099 is $2 \%$ which falls below the range reported by the Higher Education Statistics Agency in the UK (HESA) in 2020-2021, which reported a 7-11\% increase in assessment scores during the pandemic (HESA, January 2021). In EL111, the increase is $9 \%$, which falls within the range reported by HESA, and in EL112, it is $2 \%$, which again falls below the figures reported by HESA.

It is worth mentioning that for EL099 zero-credit courses, students get more support to settle in; whether in an online environment or an on-campus one, taking into consideration their cultural shift from school to University studying as well as the need to support their competency having achieved a low score originally in the placement test. EL111 has the largest cohort of EFL learners traditionally and display an array of competencies ranging from elementary to lower intermediate and intermediate, which may have featured differently in the percentages, based on the clusters taking the assessment rather than the mode of assessment. EL111 results, however, fall within the HESA range. In EL112, the pass rate does not indicate a noticeable difference in online exams, with a $2 \%$ increase.

\section{Chart (15)}

Most used tools during lockdown

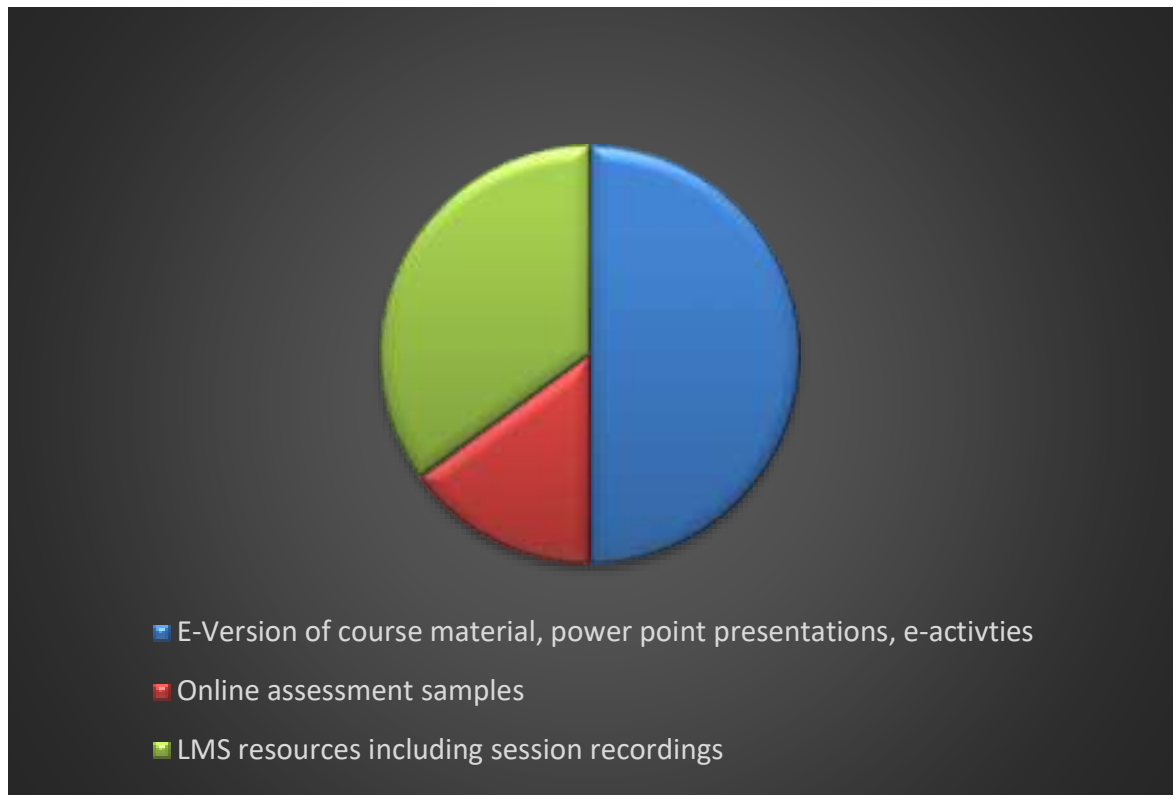

Teaching and learning practices during lockdown made use of blended methods accessed from traditional as well as distance learning. Favoured learning tools during lockdown were, as shown in the chart (14) above, e-versions of the course materials and e-activities associated with them, PowerPoint presentations prepared by the tutors, LMS resources, video recordings of the tutorial sessions and old assessment samples.

Pair work, group work, class discussions, etc. were not reported to be as smooth in online learning as is the case in traditional faceto-face tutorials in the beginning, yet with innovative teaching procedures, proper time management as well as diversified activities, learners were engaged in engaging quasi pair and group work modes. 


\section{Chart (16)}

Online Teaching Methods \& Engaging Students in English Communication Skills Courses

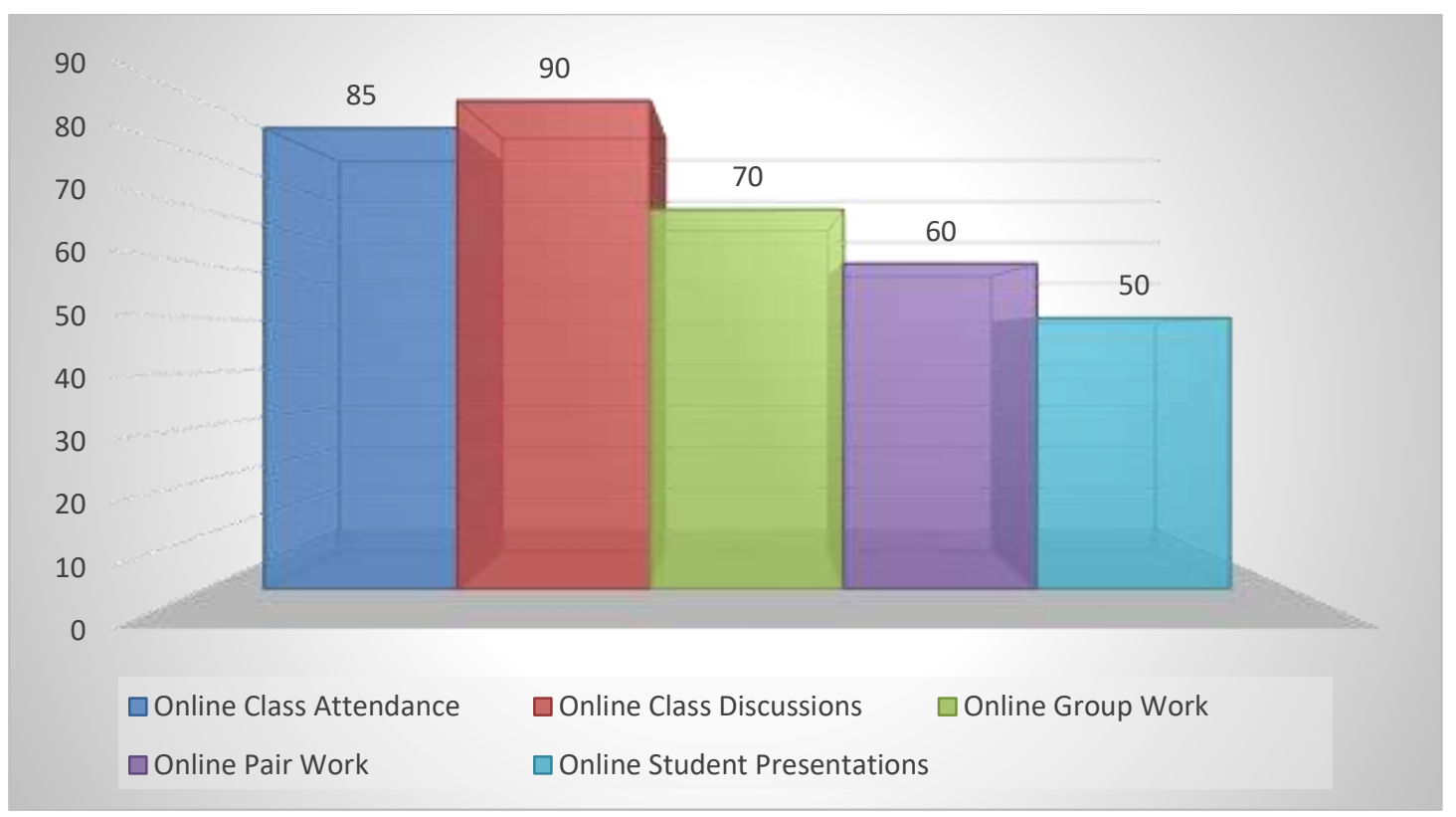

These methods were quite successful, as reflected in students' performance in exams. A slight increase in the success rate was observed, but it fell within or under HESA percentages and thus does not point to increased attempts to plagiarize.

\section{Conclusions}

The study constituted a major undertaking in evaluating and reflecting on the teaching and learning enterprise as mandated by the spread of the pandemic. It included data collected from around 1000 participants, weighing feedback from the major stakeholders in the enterprise ( $n=42$ Tutors and 911 students).

The findings confirm that English Language instructors engaged in teaching foundation modules were able to use appropriate teaching methods suitable for online teaching, which included methods from traditional teaching in addition to new interactive methods adopted and adapted to suit online teaching resources. The findings from this study challenge the propositions made by Coman et al. (2020: 1-24) that the shift to e-learning entails many problems associated with course delivery, the degree of staff expertise, student resources and engagement. They also contest Some-Guiebre's (2020) claims that "the nature of classroom interaction often determines the extent to which learners can or cannot acquire the language" (p.1) since our findings did not identify stark differences in learners' attainment, as evident in the pass rates, when shifting to a virtual classroom.

The virtual learning centres were utilized to continue to provide support in EFL teaching, and learning and students were encouraged to participate in the activities of the virtual English Language Speaking and Writing Centres, where they were provided with speaking support in interactive sessions as well as additional material for writing practices. The similarities between online and on-campus teaching methods underlined the role of careful preparations and proper time management, in addition to diversifying activities to engage the learners in various ways. The differences reported by the instructors and learners relate to the learners' commitment to online learning and their new role of assuming more responsibility in their EFL learning. Technical skills and the ability to work with technological resources to manage the assigned work were also underlined as a new necessity in learning under the lockdown situation. Definitely, the new role assumed by the learners differs from their role in traditional learning, where they rely more on instructors to provide content and guidance. However, findings of our study have revealed that online learning appears to have allowed students to successfully cope with course material at their own pace, retrieve tutorials if they have work schedule restrictions and enjoy unlimited access to the recorded sessions. The reported technical difficulties pertaining to logging in and accessing the online provisions were withered with the intervention of student support technical teams and improved student practice. 
The pass rates confirmed that the measures that were taken to curb plagiarism seemed to deter students from attempting to cheat, and as a result, the pass rates did not demonstrate a drastic or significant increase. In addition, the timed online assessments such as in-class quizzes and long controlled writing tasks or what is called in-class TMAs curbed attempts to resort to external help. Some weak students may resort to external help or tend to plagiarize in assessments, and this problem has been universally acknowledged. Nonetheless, the use of plagiarism detection software like Turnitin and identifying weak students during online sessions, using timed online quizzes, attendance and absence records, and applying the non-tolerance AOU policy on plagiarism served to deter such inclinations.

Therefore, in terms of positioning our study in relation to conflicting views arising from the debate on whether teaching and learning under lockdown situations would "never match the real thing" (Zipin 2020 and others), we can argue that this can be possible provided that specific conditions are met.

\subsection{Implications}

This study has implications in the areas of teacher training, textbook writing and assessment preparation. The study results indicate that diversifying the teaching methods to incorporate traditional resources of content and tutor input, in addition to technical resources and provisions, need to be taken into consideration in planning curricula and study calendars. Teacher training needs to incorporate digital technology skills and share best practices during the pandemic period. These measures were followed by the AOU and were conducive to achieving positive results.

Academic institutions, and the world in general, were not ready for a pandemic of this size and had not put it in risk management plans. As a result, tutors had to find ways of dealing with teaching and assessment under lockdown and improvise as the situation unfolded. Students, too, had to study under unexpected conditions; 410 out of 911 students surveyed (45\%) indicated that it was their first encounter with online teaching and learning, which is unanticipated and quite challenging. The Arab Open University managed to cope because it was one of the academic institutions that already have an online component in its blended teaching and learning strategy, which contributed to the success of its endeavour in dealing with teaching and learning under lockdown scenarios. Such a situation may recur in the future, for another reason, so it is recommended that academic institutions should have felicitous plans for teacher training and develop teaching and learning methods apt for online schooling under unexpected situations, as the future is unpredictable. Textbook writers and publishing houses should prepare e-versions of their textbooks and other supporting materials equipped with e-stimulating activities that compensate for the face-to-face ones that engage EFL learners in a learning atmosphere that is similar, if not better to the traditional model of schooling. Besides this, both academic institutions and textbook writers should innovate in the areas of assessment in such a way that EFL skills are tested online with a high level of reliability, validity and means of assessment delivery.

Online teaching and learning contributed to enhancing a number of 21st-century skills like computer literacy and independent education. It supported lifelong learning by encouraging the use of technical tools in researching, sharing experiences and presenting assigned activities. Instructors and students became technically adept and were able to cope with the assigned online tasks.

\section{References}

[1] Al-Zahrani, M. Y., \& Al-Bargi, A. (2017). The impact of teacher questioning on creating interaction in EFL: A discourse analysis. English Language Teaching, 10(6), 135-150.

[2] Amatari, V. O. (2015). The instructional process: A review of Flanders' interaction analysis in a classroom setting. International Journal of Secondary Education, 3(5), 43-49.

[3] Champakaew, W., \& Pencingkarn, W. (2014). The effectiveness of negotiation for meaning strategies on EFL learners' oral proficiency development in two-way communication tasks. The New English Teacher, 8(1), 80 - 101.

[4] Coman, C., Tîru, L., Mesesan-Schmitz, L. Stanciu, C. \& Bularca, M. (2020). Online Teaching and Learning in Higher Education during the Coronavirus Pandemic. Sustainability 2020 (12). 1-24. doi:10.3390/su122410367.

[5] Elers, S. (2020). Education institutes around the world scramble to prepare for online teaching. Stuff on Social and Cultural Issues. March 21. https://www.stuff.co.nz/national/health/coronavirus/120400677/education-institutes-around-the-world-scramble-to-prepare-for-onlineteaching

[6] Giano, Z. (2020). Book review of The Privileged Poor: How Elite Colleges Are Failing Disadvantaged Students by Jack, A. Family and Consumer Sciences Research Journal 48 (4). June 2020. https://onlinelibrary.wiley.com/doi/10.1111/fcsr.12361

[7] Gino, F. (2016). Cognitive Fatigue Influences Students' Performance on Standardized Tests. Proceedings of the National Academy of Sciences 113, no. 10 (March 8, 2016). 
[8] Higher Education Student Statistics: UK, (2019/20) - Qualifications achieved. January 21 2021. https://www.hesa.ac.uk/news/27-012021/sb258-higher-education-student-statistics/qualifications

[9] Hu, R., \& Zhang, G. (2020). A survey study of middle school English instruction in four rural districts in Beijing. International Journal of Educational Methodology, 6(1), $99-112$

[10] Jenkins, D. (2020). The Dual Enrollment Playbook: A Guide to Equitable Acceleration for Students. Community College Research Centre, Columbia University.

[11] Karatas, H. Alci, B. and Aydin, H. (2013). Correlation among high school senior students' test anxiety, academic performance and points of university entrance exam. Educational Research and Reviews Vol. 8(13.). 919-926.

[12] Kadlec, A. (2006). Reconstructing Dewey: The Philosophy of Critical Pragmatism. Polity 38, 519-542. https://doi.org/10.1057/palgrave.polity.2300067

[13] Metro, R. (2020). Humane Assessment Shouldn't Happen Only During a Pandemic. Inside Higher Education. September 9. https://www.insidehighered.com/views/2020/09/09/new-approaches-assessment-can-promote-student-success-times-crisis-well-normalcy

[14] Online Education Trends Report -(2021): An Annual Survey of Students and School Administrators. In

[15] https://www.bestcolleges.com/research/annual-trends-in-online-education date of access 8/9/2021.

[16] Qashoa, S. H. (2013). Effect of teacher question types and syntactic structures in EFL classroom interaction. International Journal of Social Sciences, 7(1), 52-62.

[17] St. Amour, M. (2020). As Times and Students Change, Can Faculty Change, Too? Inside Higher Education. April 3. https://www.insidehighered.com/news/2020/04/03/faculty-face-uphill-battle-adapting-needs-todays-students

[18] Stommel, J., Friend, C., Morris, S., Rorabaugh, P., Rheingold, H., Watters, A., Davidson, C., Stewart, B. \& Benjamin, R. (2020). Critical Digital Pedagogy. Hybrid Pedagogy.

[19] Vebriyanto, D. A. (2015). Teacher's questions in EFL classroom interaction. Journal for Language and Foreign Language learning, 4(2), 279298. https://doi.org/10.21580/vjv4i21595

Some-Guiebre, E. (2020). Foreign language classroom Interaction: Does it promote communicative skills? International Journal of Educational Methodology, 6(3), 497-505. https://doi.org/10.12973/ijem.6.3.497

[20] Walsh, S. (2011). Exploring classroom discourse: Language in action. Routledge.

[21] Zipin, L. (2020). Building curriculum knowledge work around community-based "problems that matter": Let's dare to imagine. Curriculum Perspectives, 40 (1), 111-115. https://doi.org/10.1007/s41297-019-00096-y

\section{Appendix 1}

\section{Dear AOU Tutor,}

FLS is collecting data for a study project on teaching and learning English during Covid-19. You are kindly requested to share your feedback on the following questions:

\begin{tabular}{|c|c|c|}
\hline \multicolumn{3}{|c|}{ Branch } \\
\hline \multicolumn{3}{|c|}{ Tutor's name } \\
\hline \multicolumn{3}{|c|}{ Course(s) taught } \\
\hline & Questions & Responses \\
\hline 1 & Were you teaching online or on-campus, or both? & \\
\hline 2 & $\begin{array}{l}\text { How similar or different were the teaching methods utilized virtually } \\
\text { as compared to traditional face-to-face ones? }\end{array}$ & \\
\hline 5 & $\begin{array}{l}\text { Could you give examples of the most effective virtual teaching } \\
\text { methods you used? }\end{array}$ & \\
\hline 6 & $\begin{array}{l}\text { How effective were these methods used virtually as reflected in } \\
\text { students' performance in different types of assessments? }\end{array}$ & \\
\hline 8 & $\begin{array}{l}\text { Could you recall any effective online platforms/tools used to engage } \\
\text { students and get their feedback? Give examples, please. }\end{array}$ & \\
\hline
\end{tabular}




\begin{tabular}{|l|l|l|}
\hline 9 & $\begin{array}{l}\text { How do you compare the students' attendance in on-campus to } \\
\text { online sessions (use percentages, for example, less than } 25,30 \%, \\
\text { more than } 75 \%) ?\end{array}$ & \\
\hline 10 & $\begin{array}{l}\text { To what extent are the online exams reliable, valid, and test language } \\
\text { skills properly? } \\
\text { (The reliability of an assessment is the extent to which it measures } \\
\text { students' learning consistently. The validity of an assessment is the } \\
\text { extent to which an assessment measures what it was designed to } \\
\text { measure). }\end{array}$ & \\
\hline
\end{tabular}

\section{Appendix 2: Student Survey}

Student survey to identify the degree of student adaptation to the change in teaching and learning during Covid-19.

Dear ELU Student,

If you are enrolled in EL099, EL111 or EL112, then please read the following statements and choose the answer that best reflects your opinion.

$1=$ Strongly disagree

$2=$ Disagree

$3=$ Neutral

$4=$ Agree

$5=$ Strongly agree

1. The quality of the Internet was a main challenge in my online studying.
a. strongly agree
b. agree c. neutral
d. disagree e. strongly disagree

2. Electricity was not always available in my area.
a. strongly agree
b. agree c. neutral
d. disagree e. strongly disagree

3. During online session time, the teacher presents and students are mostly silent.
a. strongly agree
b. agree c. neutral
d. disagree e. strongly disagree

4. In online teaching, group work was impossible.
a. strongly agree
b. agree c. neutral
d. disagree e. strongly disagree

5. Sometimes the quality of teacher's voice was unclear.
a. strongly agree
b. agree c. neutral
d. disagree e. strongly disagree

6. Sometimes the teachers put all students in 'silent mode' to minimize noise.
a. strongly agree
b. agree c. neutral
d. disagree e. strongly disagree

7. Sometimes the teachers asked students not to use their cameras and just listen to lessen the load of the Internet.
a. strongly agree
b. agree c. neutral
d. disagree e. strongly disagree

8. Quizzes are better conducted online than in face-to-face teaching.
a. strongly agree
b. agree c. neutral
d. disagree e. strongly disagree

9. Teacher gives feedback after exams.
a. strongly agree
b. agree c. neutral
d. disagree e. strongly disagree

10. One of the disadvantages in online teaching is that spoken interaction is minimized.
a. strongly agree
b. agree c. neutral
d. disagree e. strongly disagree

11. In online teaching, teachers do not correct my grammar or pronunciation when I answer questions or give a short presentation.
a. strongly agree
b. agree c. neutral
d. disagree e. strongly disagree

12. One of the difficulties of online learning is that we are more than one at home, and we have one computer only.
a. strongly agree
b. agree c. neutral
d. disagree e. strongly disagree

13. When doing quizzes, we were warned not to share answers with anyone.
a. strongly agree
b. agree c. neutral
d. disagree e. strongly disagree

14. In final exams, we never used Google because the questions were tailored in such a way that the Internet could not help.
a. strongly agree
b. agree c. neutral
d. disagree e. strongly disagree 
15. In final exams, we never used Google because the teacher made it clear that if he found answers from the Internet the student will get zero.
a. strongly agree
b. agree c. neutral
d. disagree e. strongly disagree

16. I think I learned through online teaching more than I learned through face-to-face mode.
a. strongly agree
b. agree c. neutral
d. disagree e. strongly disagree

17. Studying online made me participate, although I am usually shy.
a. strongly agree
b. agree c. neutral
d. disagree e. strongly disagree

18. Studying online motivated me to use the Internet more than before to learn by myself.
a. strongly agree
b. agree c. neutral
d. disagree e. strongly disagree

19. My marks in exams are higher than my marks in face-to-face learning.
a. strongly agree
b. agree c. neutral
d. disagree e. strongly disagree

20. I use the Internet to get answers for my quizzes and exams.
a. strongly agree
b. agree c. neutral
d. disagree e. strongly disagree

21. Online teaching turned out to be better than I expected.
a. strongly agree
b. agree c. neutral
d. disagree e. strongly disagree

22. I am looking forward to going back to face-to-face learning.
a. strongly agree
b. agree c. neutral
d. disagree e. strongly disagree

23. Changing the Writing Center and the English Speaking Skills Center into online forums has been helpful.
a. strongly agree
b. agree c. neutral
d. disagree e. strongly disagree

24. I benefited from the help my teachers extended to me during their online office hours.
a. strongly agree
b. agree c. neutral
d. disagree e. strongly disagree

25. Final Take-Home Exams (FTHEs) are as challenging as on-campus exams.
a. strongly agree
b. agree c. neutral
d. disagree e. strongly disagree

26. Our teachers' style of teaching prepared me for the Final Take-Home Exams.
a. strongly agree
b. agree c. neutral
d. disagree e. strongly disagree

\section{Demographic factors:}

- Branch:
a. Kuwait
b. Egypt
c. Lebanon
d. Saudi Arabia
e. Jordan
f. Sudan
g. Bahrain
h. Oman

- Current Course:
a. EL099
b. EL111
c. EL112

- Gender:
a. Female
b. Male

- Have you taken a face-to-face ELU course on campus (before the Covid-19 pandemic)?
a. Yes
b. No 